\title{
Research on multi objective planning optimization of integrated energy system with economic and low carbon objectives
}

\author{
Rong Chen ${ }^{1}$, Zejun Jia ${ }^{1}$, Yongli Wang ${ }^{2}$, Feifei Huang ${ }^{2}$, Yuze $\mathrm{Ma}^{2, *}, \mathrm{Xu} \mathrm{\textrm {Han } ^ { 2 }}$ \\ ${ }^{1}$ State Grid Zhenjiang Power Supply Company, Zhenjiang 212000, China \\ ${ }^{2}$ School of Economics and Management North China Electric Power University, Changping District, Beijing 102206, China
}

\begin{abstract}
In response to the global energy crisis, the integrated energy system has become an important part of the energy revolution. Aiming at the economic operation of the Integrated Energy System (IES), this paper proposes a system optimization planning model that takes the economic and environmental optimization as the goal and establishes a coupled capacity planning system, and jointly optimizes the capacity configuration and configuration of a single energy supply module. Power output to pursue maximum benefit. In order to illustrate the advantages of this method, on the basis of simulation, a dynamic programming method is used to solve the model. Finally, the simulation results show the effectiveness of the planning optimization model proposed in this paper, and provide a new path for solving the optimization problem of integrated energy system planning.
\end{abstract}

\section{Introduction}

With the advancement of industrialization and social and economic development, the world is facing severe energy crisis and environmental problems. In order to solve the increasingly severe energy and environmental dilemma, an integrated energy system came into being [1]. Different forms of energy subsystems in different and traditional energy systems are independent of each other. The integrated energy system coordinates and integrates different forms of energy. Under the premise of ensuring reliability, it can make full use of available energy, and finally realize the entire the economic operation of the system and the improvement of energy efficiency. However, this also makes the integrated energy system reflect its inherent complexity in the early stage of planning and design [2].

Research on the planning and optimization of the integrated energy system, by making full use of the complementary and alternative characteristics of different forms of energy such as electricity, gas, cold/heat in the system, and coordinated planning for the supply system of different forms of energy throughout the life cycle. It can suppress the uncertainty of renewable energy output in the system, realize the cascade utilization of energy, effectively improve the comprehensive utilization efficiency of energy, and promote the development and utilization of renewable energy [3]. In the Ref [4], based on the demand response mechanism of electro-thermal IES, a multi-objective operation optimization model with economic benefits and comprehensive energy efficiency as objective functions is established for the first time. The results show that the model can effectively improve the economic benefits and comprehensive energy efficiency of industrial enterprises, and reduce pollutant emissions to a certain extent. In the Ref [5], the planning optimization of integrated energy system is carried out with the objectives of economy, environment and reliability. The research shows that the proposed design optimization has high performance in supporting economic design, improving independent operation, reducing carbon emission and meeting various loads. In the Ref [6], the comprehensive energy system was planned under the quota condition, and the three benefits of economy, environment and society were realized.

\section{Features of integrated energy system architecture for industrial parks}

The construction of industrial park is the need to accelerate the process of industrialization and urbanization. However, the energy utilization efficiency of industrial park is low, and the contradiction between energy and resources, environment and social development is increasingly prominent. Therefore, it is necessary to focus on clean and low-carbon energy, improve energy utilization efficiency, establish an efficient, clean and low-carbon energy industrial system, and it is particularly critical to build an integrated energy system for Industrial Parks [7]. The optimal scheduling and management of regional integrated energy system is generally carried out through the energy management and control platform. The energy management and control platform is mainly composed of basic energy unit, new energy production unit, energy coupling unit and storage unit. The typical energy flow diagram of the integrated energy system is shown in Figure 1.

\footnotetext{
* Corresponding author: mayuzebj@163.com
} 
The industrial park has a variety of production capacity, which is a complex energy system mainly based on industrial load, involving the production, conversion, storage and use of electricity / heat / gas / cooling and other energy sources. With large load demand, high degree of automation, complex load characteristics and high reliability of power supply, higher requirements are put forward for the operation and dispatching of power distribution system [8]. It is necessary to plan and design a reasonable industrial park level integrated energy system construction scheme to solve the problems of low coupling degree between multi energy flows and weak collaborative interaction of industrial energy system.

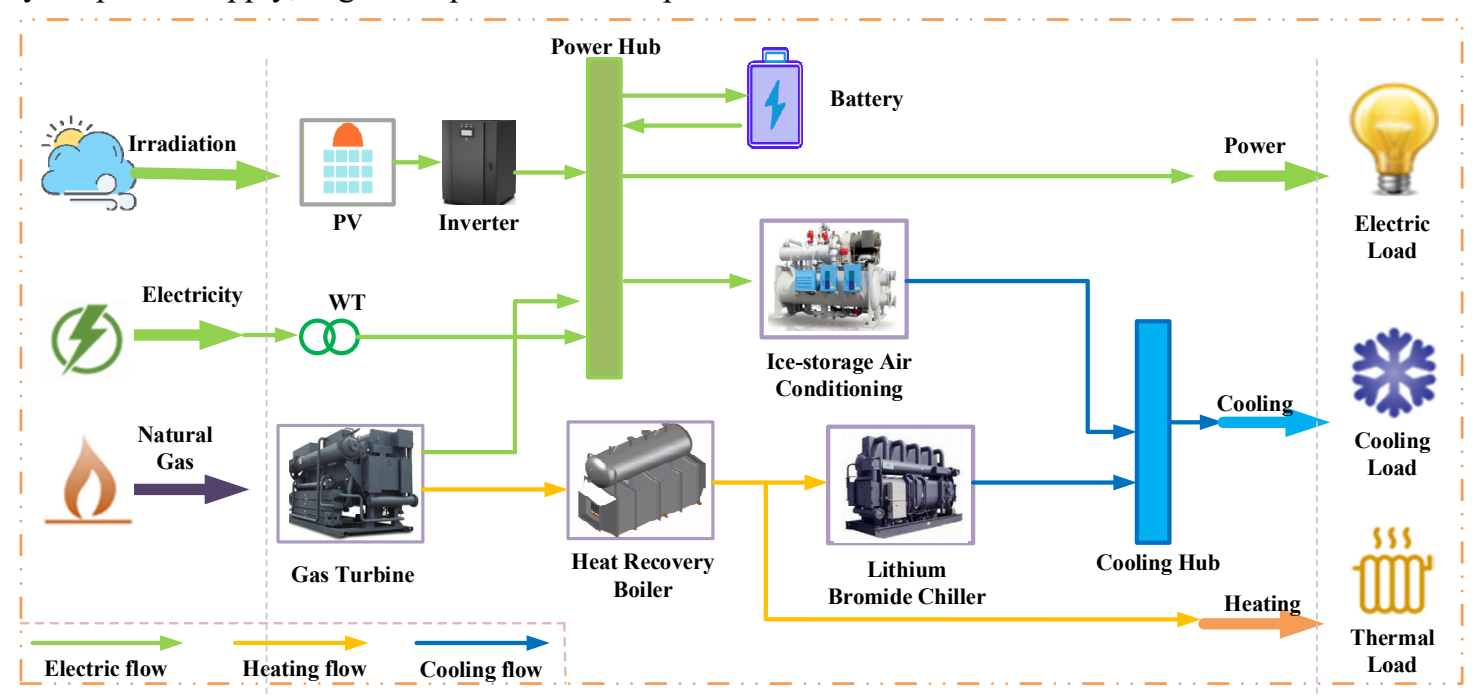

Fig1. Typical energy flow diagram of integrated energy system.

\section{Optimal modeling and solution of integrated energy system planning}

\subsection{Objective function}

On the basis of combing the relevant literature on the planning and optimization of integrated energy systems at home and abroad [9-10], it is proposed that the objectives of the integrated energy system planning and optimization in this paper are mainly around the lowest total cost during the life cycle, and the lowest carbon emission in the whole life cycle.

\subsubsection{The lowest total cost in the whole life cycle}

The total cost during the whole life cycle mainly includes the construction cost during the whole life cycle of the integrated energy system, the operating cost of purchasing energy during the operation of the integrated energy system, and the maintenance cost of the integrated system, etc., and excludes the government's contribution to the integrated energy system. Subsidy income. The objective function is:

$$
\left\{\begin{aligned}
& F=\min \left(C_{i n}+C_{q}+C_{n c}-C_{b t}\right)=\sin \left(f_{i n}(x)+f_{p}(p)+f_{n c}(p)-f_{b t}(p)\right) \\
& C_{i n}=f_{i n}(x) \\
& C_{p p} f_{q p}(p) \\
& C_{n c}=f_{m c}(p) \\
& C_{t c}=f_{b t}(p)
\end{aligned}\right.
$$

In the formula, $f_{\text {in }}(x)$ is the system investment and construction cost, $\mathrm{x}$ is the decision variable for planning and construction (the number of each equipment); $f_{o p}(p)$ is the system operating cost during the life cycle, that is, the cost of purchasing natural gas and purchasing electricity from the grid; $f_{m c}(p)$ is System maintenance cost; $p$ is the output variable of each equipment during system operation.

1) Construction cost

The initial construction cost of the integrated energy system is mainly composed of equipment purchase cost, installation cost, land cost and other expenses, namely:

$$
f_{i n}(x)=\frac{r(1+r)^{y}}{(1+r)^{y}-1}\left(\sum_{i=1}^{n} c^{i} x^{i}+\sum_{i=1}^{n} j^{i} x^{i}+\sum_{i=1}^{n} t^{i} x^{i}+e l\right)
$$

In the formula, $\mathrm{y}$ is the expected service life of the system, and $\mathrm{r}$ is the discount rate; $c^{i}$ is the cost of purchasing a single unit of different types of equipment; $x^{i}$ is the optimal number of different types of equipment in the planning optimization results; $j^{i}$ is the occupancy of each equipment in the integrated energy system The cost of land use; $t^{i}$ is the installation cost of a single unit of different types of equipment; $e l$ is the remaining cost in the construction phase.

2) Operating cost

The system operating costs that need to be considered in the planning stage of the integrated energy system mainly include: fuel consumption costs during the entire life cycle and electricity purchase costs. The formula is as follows:

$$
f_{\text {op }}(p)=\sum_{i=1}^{n} P^{i} \eta^{i}+\sum_{i=1}^{n} G^{i} \kappa^{i}
$$


Where: $P^{i}$ is the operating output of the i-th equipment; $\eta^{i}$ is the power consumption proportional coefficient of the i-th equipment; $G^{i}$ is the output of the i-th natural gas-consuming equipment, $\kappa^{i}$ is the gas consumption proportional coefficient of the i-th equipment.

3) Maintenance cost

$$
f_{m c}(p)=\sum_{i=1}^{n} x^{i} w^{i}
$$

In the formula: $f_{m c}(p)$ is the maintenance cost of all equipment in the whole life cycle; $w^{i}$ is the maintenance cost of a single device.

\subsubsection{The lowest total carbon emissions during the whole life cycle}

The objective function for the lowest carbon emissions is as follows:

$$
F=y \sum_{i=1}^{n} x^{i} N^{i}
$$

In the formula: $y$ is the entire system life cycle, $N^{i}$ is the carbon emission of $i$ equipment in the unit cycle.

\subsection{Constraints}

The constraints in the planning and design stage of the integrated energy system are as follows:

\subsubsection{Investment capacity constraints}

$$
T_{\max } \geq f_{\text {in }}(x)
$$

In the formula: $T_{\max }$ is the maximum investment capacity for the construction of an integrated energy system.

\subsubsection{Constraints on building area}

The installation of the integrated energy system must consider the amount of resources and the size of the installation site. The formula is as follows:

$$
\sum_{i=1}^{n} x^{i} m^{i} \leq A Z_{\max }
$$

In the formula: $m^{i}$ is the land area occupied by the installation of the i-th device, and $A Z_{\max }$ is the usable land area that can be used to build an integrated energy system. For building area constraints, each device also needs to consider the constraints of exclusive land area, and the geographic location of integrated energy system construction needs to be considered. For example, when solar photovoltaic panels are installed on the roof of a building, the maximum effective light area on the roof of the building must be the constraint.

\subsubsection{Grid energy supply constraints}

$$
\begin{gathered}
D_{\max } \geq \sum_{i=1}^{n}\left(x^{i} P_{\max }{ }^{i}-x^{i} U_{\max }{ }^{i}\right) \\
\sum_{i} U_{\max }{ }^{i}+D_{\max } \geq S \cdot L_{\text {max }}^{q}
\end{gathered}
$$

In the formula, $D_{\max }$ is the maximum power supply capacity of the grid, $P_{\max }{ }^{i}$ is the power consumption of the $\mathrm{i}$-th device, $U_{\max }{ }^{i}$ is the power generation of the $\mathrm{i}$-th device, $L_{\text {max }}^{q}$ is the power load designed in the integrated energy system park, and $\mathrm{S}$ is the safe power use coefficient.

\subsubsection{Operational constraints of energy supply equipment}

$$
\left\{\begin{array}{l}
\mathrm{Q}^{i}{ }_{\text {min }} \leq Q \leq Q_{\text {max }}{ }^{i} \\
-\Delta \mathrm{Q}^{i}{ }_{\text {down }} \leq Q_{t}{ }^{i}-Q_{t-1}{ }^{i} \leq \Delta Q_{u p}{ }^{i}
\end{array}\right.
$$

Where: $\mathrm{Q}^{i}{ }_{\min }$ and $Q_{\max }{ }^{i}$ are the minimum power and maximum power of the $\mathrm{i}$-th equipment for cooling/heating, respectively; $\mathrm{Q}^{i}{ }_{\text {down }}$ and $\Delta Q_{u p}{ }^{i}$ are the ramp rates of the $\mathrm{i}$-th equipment when the output is reduced or increased.

\subsection{Optimization algorithm}

From the perspective of mathematical models, the planning and optimization of integrated energy systems involve complex constraints, and the dimensionality of the solution is high when performing multi-objective optimization, which is a typical nonlinear programming problem.

The dynamic programming method was proposed by Polman in 1957. It is a method of decomposing the original multi-stage complex problem into relatively simple sub-problems to obtain the optimal solution, that is, the sub-strategy contained in the optimal strategy must be the optimal sub-strategy. Strategy. The state recursive formula of the dynamic programming algorithm in the integrated energy system is as follows:

$$
\min F=\sum_{k}^{N-1} F_{k}\left(x_{k}, u_{k}\right)+F_{N}\left(x_{N}, u_{N}\right)
$$

$N$ is the total number of planning stages; $x_{k}$ is the state variable of the $\mathrm{k}$-th stage, that is, the output power of the energy production equipment; $F_{k}\left(x_{k}, u_{k}\right)$ is the index equation of the $\mathrm{k}$-th stage. The state transition equation is:

$$
x_{k+1}=g\left(x_{k}, u_{k}\right)
$$

$u_{k}$ is the decision variable of the k-th stage, that is, the adjustable output power of the integrated energy system. The expression is as follows: 


$$
x(t)=\left[\begin{array}{llll}
\Delta P_{w} & \Delta P_{g} & \ldots & \Delta P_{e}
\end{array}\right]
$$

\section{Case study}

This paper selects a park-level integrated energy project in northern China as the research object to verify the reliability of the planning optimization model established. According to the predicted wind speed, light intensity and energy consumption of the park, the energy output and load demand of the park are calculated, and the running time is 24 hours. The natural gas price in the park adopts a fixed gas price of 2.45 yuan $/ \mathrm{m}^{3}$. The electricity price adopts the time-of-use electricity price, in which the electricity price in the peak period (8:00-11:00\&17:00$21: 00$ ) is 1.42 yuan $/ \mathrm{kW}$, and the electricity price in the valley section $(21: 00-8: 00)$ is 0.47 yuan $/ \mathrm{kW}$. The electricity price for the segment $(11: 00-17: 00)$ is 0.97 yuan $/ \mathrm{kW}$.

According to the general principles of the integrated energy planning stage, it is assumed that renewable energy power generation is completely consumed, so that wind turbines and photovoltaic power generation are used $100 \%$. The CCHP system supplies heat and cold loads, and ice storage units and other electric refrigeration equipment supply cold loads. The function of setting energy storage equipment in the system is to shift the output fluctuation of production equipment, respond to load changes, and enhance the reliability of electricity use. The optimal capacity allocation results and cost structure are shown in Table 2 and Table 3.
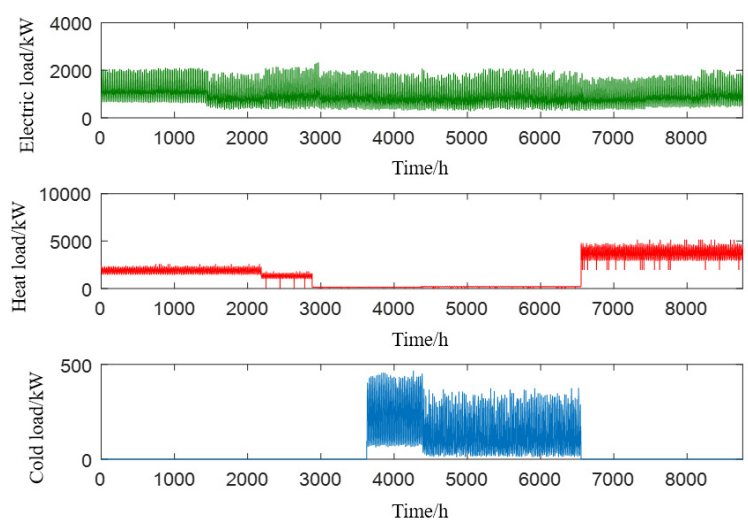

Fig2. Forecast of the park's annual electricity, heating and cooling loads.
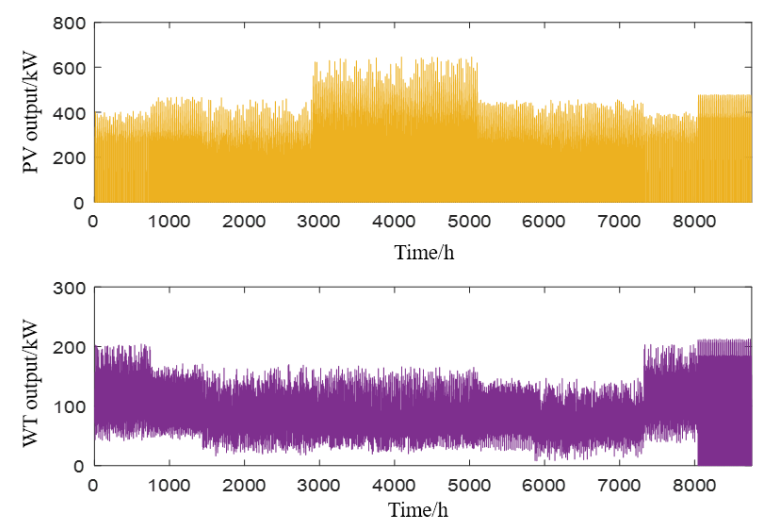

Fig3. Forecast of annual output of photovoltaic and wind turbines in the park.

Table 1 Details of equipment cost.

\begin{tabular}{|l|c|c|c|c|c|c|}
\hline Equipment & PV & WT & Gas turbine & $\begin{array}{c}\text { Lithium } \\
\text { Bromide Unit }\end{array}$ & $\begin{array}{c}\text { Energy storage } \\
\text { battery }\end{array}$ & Ice storage unit \\
\hline Acquisition cost & 5000 & 7600 & 5000 & 1800 & 2000 & 4000 \\
\hline $\begin{array}{l}\text { Annual operation } \\
\text { and maintenance } \\
\text { costs }\end{array}$ & 4.3 & 7.21 & 3800 & 520 & 1100 & 450 \\
\hline
\end{tabular}

Table 2 Capacity configuration results.

\begin{tabular}{|l|c|c|c|c|c|c|}
\hline Equipment & PV(MW) & WT(MW) & $\begin{array}{l}\text { Gas } \\
\text { turbine(MW) }\end{array}$ & $\begin{array}{l}\text { Lithium } \\
\text { Refrigerator(MW) }\end{array}$ & $\begin{array}{l}\text { Energy storage } \\
\text { battery(MWh) }\end{array}$ & Ice storage(MWh) \\
\hline $\begin{array}{l}\text { Installed } \\
\text { capacity }\end{array}$ & 12.25 & 4.63 & 16.52 & 4.31 & 22.58 & 11.13 \\
\hline
\end{tabular}

Table 3 Cost structure.

\begin{tabular}{|c|c|c|c|c|c|}
\hline & $\begin{array}{c}\text { Initial equipment } \\
\text { investment (ten } \\
\text { thousand yuan) }\end{array}$ & $\begin{array}{c}\text { Annual investment } \\
\text { (ten thousand } \\
\text { yuan) }\end{array}$ & $\begin{array}{c}\text { Annual } \\
\text { maintenance fee } \\
\text { (ten thousand } \\
\text { yuan) }\end{array}$ & $\begin{array}{c}\text { Energy purchase } \\
\text { cost (ten thousand } \\
\text { yuan) }\end{array}$ & $\begin{array}{c}\text { Carbon } \\
\text { emission/kg }\end{array}$ \\
\hline $\begin{array}{c}\text { Estimated } \\
\text { configuration plan }\end{array}$ & 72529.76 & 5838.65 & 28.93 & 125176.64 & 419769.78 \\
\hline
\end{tabular}

\section{Conclusion}

In this article, the characteristics of the integrated energy system architecture for industrial parks are described, and the planning optimization method for the system capacity configuration and dispatching scheme in the integrated energy system is proposed. Based on the dynamic programming algorithm, the capacity of the integrated energy energy supply equipment is reasonably allocated with the goal of economic and environmental optimization. In addition, in order to verify the validity of the model constructed in this paper, a simulation study is carried out. The final simulation results show that the theoretical method proposed in this paper has reached the best economy of the system, and strictly controlled the 
pollutant emissions produced by RIES. In the future, the coordination mechanism between comprehensive capacity planning of the energy system and system operation will be further studied to achieve a balance between system capacity configuration and operation optimization, so as to reduce costs as much as possible and improve energy supply efficiency.

\section{Acknowledgments}

This paper was supported by "Management consulting project of State Grid Zhenjiang Power Supply Company (SGJSZJ00FZWT2000601)".

\section{References}

1. Sun HB, Guo QL, Pan ZG, et al. Energy Internet: Driving Forces, Comments and Prospects [J]. Power System Technology, 2015, (11): 3005-3013.

2. Jia HJ, Mu YF, Yu XD. Thoughts on the development of my country's integrated energy system[J]. Electric Power Construction, 2015, 36(1): 16-25.

3. Sadreddini A, Fani M, Aghdam M A, et al. Exergy analysis and optimization of a CCHP system composed of compressed air energy storage system and ORC cycle $[\mathrm{J}]$. Energy Conversion \& Management, 2018, 157:111-122.

4. 4Wang Y, Ma Y, Song F, et al. Economic and efficient multi-objective operation optimization of integrated energy system considering electro-thermal demand response[J]. Energy, 2020, 205:118022.

5. Wang YL, Wang $\mathrm{X}$, Yu H, et al. Optimal design of integrated energy system considering economics, autonomy and carbon emissions[J]. Journal of Cleaner Production, 2019.

6. Wang YL, Guo L, Zhou MH, et al. Study on planning benefit of integrated energy system based on quota investment $[\mathrm{J}]$. Power demand side management, $2020(5)$.

7. Jia HJ, Wang D, Xu XD, et al. Research on Several Issues of Regional Integrated Energy System[J]. Automation of Electric Power Systems, 2015, 39(7): 198-207.

8. Zhou CH, Zheng JH, Jing ZX, et al. Multi-objective optimization design of integrated energy system for park microgrid[J]. Power System Technology, 2018, 42(6): 1687-1697.

9. Wang YL, Yu HY, Yong MY, et al. Optimal Scheduling of Integrated Energy Systems with Combined Heat and Power Generation, Photovoltaic and Energy Storage Considering Battery Lifetime Loss[J], Energies, 2018, 11(7): 1676-1679.

10. Wang YL, Dong HR, Qi CY, et al. Research on Optimization and Regulation Methods of Ubiquitous Power Internet of Things[J]. Power Demand Side Management, 2019, 21(6): 8-13. 